\title{
HIV e Leishmaniose tegumentar americana no estado de Sergipe: um estudo do espectro disseminado da coinfecção
}

Em pacientes co-infectados por HIV, a Leishmaniose tegumentar americana (LTA) comumente se torna disseminada, além de apresentar manifestacões atípicas e mais graves, devido a Em pacientes co-infectados por HIV, a Leishmaniose tegumentar americana (LTA) comumente se torna disseminada, além de apresentar manifestaçóes atipicas e mais graves, devido à padrão, com alta taxa de recidiva. O presente estudo elucida uma descrição de caso admitido no Hospital de Urgências de Sergipe (HUSE), com análise de diagnóstico e conduta baseada na padrão, com alta taxa de recidiva. O presente estudo elucida uma descrição de caso admitido no Hospital de Urgências de Sergipe (HUSE), com análise de diagnóstico e conduta baseada na
literatura referente à coinfecção LTA-HIV. Trata-se de J.B.A., 34 anos, sexo masculino, HIV positivo e com diagnóstico anterior de Tuberculose pulmonar, em uso regular de terapia antirretroviral e COXCIP, admitido no HUSE em 2018 com tosse produtiva, secreção amarelada, febre diária e dispneia aos esforços há 2 semanas. Apresentava lesões maculare hipercrômicas em face e úlcero-crostosas de bordas elevadas com variados tamanhos em membros superiores e tronco, diagnosticadas LTA via biópsia das lesões após negativação do teste sorológico rk39 por imunossupressão. Negava uso regular de profilaxias para pneumocistose e micobactérias. Iniciou-se antibioticoterapia e cateter nasal de 02. Supõe-se, portanto, que 0 desvio da resposta celular tipo Th1 para a humoral tipo Th2 no portador de HIV seja favorável à disseminação de organismos intracelulares como a leishmania. Entretanto, esse comportamento clínico-imunológico da coinfecção é pouco descrito na literatura. Ainda assim, J.B.A. apresentou excelente resposta terapêutica ao uso de Anfotericina Lipossomal. O relato desse caso alerta para o espectro clínico da coinfecção e para uma opção de tratamento viável, sobretudo em Sergipe, cuja expansão epidemiológica das doenças é evidente.

Palavras-chave: HIV; Leishmaniose; Coinfeç̧ão.

\section{HIV and American cutaneous leishmaniasis in the state of Sergipe: a study of the dissemination spectrum of co-infection}

In patients co-infected with HIV, American cutaneous leishmaniasis (ATL) commonly becomes widespread, in addition to presenting atypical and more severe manifestations due to immunosuppression. In these patients, the disease is characterized by multiple atypical lesions infested by parasites, affecting various body segments, and poor response to standard . antiretroviral therapy and COXCIP, admitted to HUSE in 2018 with productive cough, yellowish discharge, daily fever and dyspnea on exertion for a long time. 2 weeks. He had hyperchromic macular lesions on the face and crusted ulcers with elevated edges of varying sizes in the upper limbs and trunk, diagnosed with ACL via biopsy of the lesions after negative serological test rk39 by immunosuppression. He denied regular use of prophylaxis for pneumocystosis and mycobacteria. Antibiotic therapy and a nasal 02 catheter were started. It is assumed, therefore, that the deviation from the Th1 cell response to the humoral Th2 type response in HIV patients is favorable to the spread of intracellular organisms such as leishmania. However, this clinical-immunological behavior of co-infection is poorly described in the literature. Still, J.B.A. showed an excellent therapeutic response to the use of liposomal amphotericin. The report of this case alerts to the clinical spectrum of co-infection and to a viable treatment option, especially in Sergipe, whose epidemiological expansion of diseases is evident.

Keywords: HIV; Leishmaniasis; Coinfection.

Topic: Infectologia

Reviewed anonymously in the process of blind peer.
Received: $12 / 08 / 2021$

Approved: 09/09/2021
Bruno José Santos Lima

Universidade Tiradentes, Brasi

http://lattes.cnpq.br/6158584238563073

brunohd123456@gmail.com

Maylla Fontes Sandes

Universidade Tiradentes, Brasil

http://lattes.cnpq.br/8288542250707046

http://orcid.org/0000-0002-5511-0253

sandesmaylla@gmail.com

Matheus Todt Aragão

Universidade Tiradentes, Brasil

http://lattes.cnpq.br/5208980094866667

http://orcid.org/0000-0002-3585-4562

mtodt@hotmail.com

\section{Gilmara Carvalho Batista}

Universidade Tiradentes, Brasil

http://lattes.cnpq.br/141514584258320

bruno.jsantos@souunit.com.br
Dante Costa de Araújo (iD

Universidade Tiradentes, Brasil

http://lattes.cnpq.br/7145937374206565

http://orcid.org/0000-0002-3423-8928

danttecostta@gmail.com

José Abimael da Silva Santos (iD

Universidade Federal de Sergipe, Brasil

http://lattes.cnpq.br/5056576216663994

http://orcid.org/0000-0002-5076-5787

josebimael@hotmail.com

Mateus Lenier Rezende (iD

Universidade Tiradentes, Brasil

http://lattes.cnpq.br/7616614677398526

http://orcid.org/0000-0002-6965-8463

mateuslenier@gmail.com
Hélder Santos Gonçalves (iD)

Universidade Tiradentes, Brasil

http://lattes.cnpq.br/4134686304475030

http://orcid.org/0000-0001-5766-771X

heldermd2111@hotmail.com

Leonardo Santos Melo

Universidade Tiradentes, Brasil

http://lattes.cnpq.br/3797994277532039

http://orcid.org/0000-0003-0486-6031

lekosm11@gmail.com

Caroline Cordeiro Vieira (iD

Universidade Tiradentes, Brasil

http://lattes.cnpq.br/9159941422177643

http://orcid.org/0000-0001-5537-6855

carolacordeirov@gmail.com d

DOI: 10.6008/CBPC2236-9600.2021.003.0016
Referencing this:

LIMA, B. J. S.; SANDES, M. F.; ARAGÃO, M. T.; BATISTA, G. C.; ARAÚJO, D. C.; SANTOS, J. A. S.; REZENDE, M. L.; GONÇALVES, H. S.; MELO, L. S.; VIEIRA, C. C.. HIV e Leishmaniose tegumentar americana no estado de Sergipe: um estudo do espectro disseminado da coinfecção. Scire Salutis, v.11, n.3, p.126-129, 2021. DOI:

http://doi.org/10.6008/CBPC2236-9600.2021.003.0016 


\section{INTRODUÇÃO}

A leishmaniose tegumentar americana (LTA) se apresenta clinicamente sob 4 formas distintas da doença: leishmaniose cutânea, leishmaniose mucosa, leishmaniose disseminada e leishmaniose cutânea difusa. A leishmaniose cutânea, a leishmaniose mucosa e a leishmaniose disseminada no Nordeste brasileiro são causadas, principalmente, pela L. braziliensis; e a leishmaniose difusa, pela L. amazonensis.

O primeiro caso de coinfecção Leishmania-HIV foi descrito em 1985, no sul da Europa, e atualmente, há registro de sua presença em 35 países. A experiência mundial, especialmente a europeia, evidencia aumento importante do número de casos de coinfeç̧ão nesta década, levando a modificações na história natural das leishmanioses. Estudos em modelos experimentais de leishmaniose demonstraram que a resposta Th1 ou tipo 1, associada à produção de IL-2, IFN- $\gamma$ e TNF- $\alpha$, está ligada à resistência ao patógeno e cura espontânea da lesão, enquanto que a resposta tipo 2, caracterizada pela produção de IL-4 e IL-5, está associada à susceptibilidade à infecção e proliferação do parasita.

Na leishmaniose cutânea e leishmaniose mucosa, existe uma forte resposta tipo 1, o que controla a multiplicação do parasita, porém há lesão tecidual. Enquanto que, na leishmaniose disseminada e na leishmaniose cutânea difusa, a diminuição ou ausência de resposta tipo 1 favorece a multiplicação e disseminação da leishmania.

A infecção pelo HIV-1 caracteriza-se pela redução progressiva e contínua dos linfócitos T CD4+, principal alvo do vírus, em ausência de CART. Os linfócitos T CD4+ desempenham um papel importante na resposta imune contra o HIV-1 e contribuem para o controle das infecções virais de um modo geral, pela indução e/ou manutenção da resposta dos linfócitos T CD8+, linfócitos B e macrófagos, e/ou ainda pela mediação direta de suas funções efetoras antivirais, como a produção de citocinas e, eventualmente, por atividade citotóxica. Nesse viés, a coinfecção estabelece um ambiente desestruturado de células T CD4+, impactando no controle da replicação da leishmania tegumentar e em sua contenção ao sítio de infecção primária, o que aumenta muito o risco de sua forma disseminada.

Portanto, em pacientes co-infectados por HIV, a Leishmaniose tegumentar americana (LTA) comumente se torna disseminada, além de apresentar manifestações atípicas e mais graves, devido à imunossupressão. Nestes pacientes, a doença é caracterizada por múltiplas lesões atípicas infestadas por parasitos, acometendo vários segmentos corporais, e má resposta ao tratamento padrão, com alta taxa de recidiva.

\section{METODOLOGIA}

O presente estudo elucida uma descrição de caso admitido no Hospital de Urgências de Sergipe (HUSE), com análise de diagnóstico e conduta baseada na literatura referente à coinfecção LTA-HIV em seu aspecto de disseminação.

\section{DISCUSSÃO TEÓRICA}


J.B.A., 34 anos, sexo masculino, HIV positivo e com diagnóstico anterior de Tuberculose pulmonar, em uso regular de terapia antirretroviral e COXCIP. Foi admitido no Hospital de Urgências de Sergipe (HUSE) em 01 de outubro de 2018 (D1) com febre, dor torácica ventilatório dependente, tosse seca e dispneia. Negava uso regular de profilaxias para pneumocistose e micobactérias. Apresentou também lesões maculares hipercrômicas úlcero-crostosas em face, com bordas elevadas e variados tamanhos em membros superiores e tronco. Biópsia das lesões, após negativação do teste sorológico rk39 por imunossupressão, confirmou LT disseminada.

No D2, ao exame físico, apresentava-se com estado geral regular (REG), lúcido, orientado no tempo e espaço, emagrecido, hipocorado (++/4+) e eupneico. Ausculta respiratória com murmúrio vesicular (MV) presente em ambos hemitórax e com crepitação em ápice pulmonar esquerdo. Foi solicitada a radiografia de tórax, que evidenciou opacidade heterogênea em dois terços do pulmão esquerdo e opacidade homogênea em ápice pulmonar esquerdo. Aos exames laboratoriais, demonstrava anemia (Hb de 10,1 $\mathrm{g} / \mathrm{dL}$ ), linfopenia (Linfócitos de 439,8/ $\mathrm{mm}^{3}$ ) como principais alterações.

Após a avaliação, instituiu-se tratamento para pneumonia bacteriana e pneumocistose com Cefepime 2g por via endovenosa (EV) de 12 em 12 horas, 03 ampolas de Bactrim mais $300 \mathrm{ml}$ de soro glicosado a 5\% por EV de 6 em 6 horas e Azitromicina 500mg por via oral (VO) na segunda, quarta e sextafeira. Nos subsequentes, evoluiu temporariamente com melhora da dispneia e da dor torácica, além do desaparecimento dos ruídos adventícios em ápice pulmonar.

No D6, porém, retomou o quadro de dispneia aos esforços, concomitantemente a uma piora laboratorial, com houve piora da febre, tendo pico febril no D8. Novos exames laboratoriais foram solicitados, havendo queda nos níveis de hemoglobina para 9,5 g/dL e discreta melhora, apesar da permanência da linfopenia $\left(447 / \mathrm{mm}^{3}\right)$ e exame radiográfico sem alterações. Prescreveu-se Amitriptilina 25 $\mathrm{mg}$ à noite e o transferiram para enfermaria.

$\mathrm{Na}$ admissão na enfermaria (D9), referiu febre contínua, cefaleia, astenia e dispneia aos esforços. Ao exame a beira do leito, REG, frequência cardíaca de $129 \mathrm{bpm}$, febre alta (38.8 ํ) $)$, 94\% de saturação de $\mathrm{O}_{2}$ em ar ambiente, hipocorado (+/4+) e ausculta pulmonar com murmúrio vesicular presente em ambos hemitórax e com presença de roncos em hemitórax esquerdo. Ausculta cardíaca, exame do abdome e de extremidades sem alterações. No D10, houve piora do quadro, com dor torácica ventilatório depende, tosse produtiva com secreção amarelada e epigastralgia. Aos exames laboratoriais, apresentou pela primeira vez no período de internação leucocitose com 12900 céls $/ \mathrm{mm}^{3}$ e leve aumento na quantidade de linfócitos $\left(563,7 / \mathrm{mm}^{3}\right)$, associados à alcalose metabólica evidenciada pela gasometria $(\mathrm{pH}=7,48$ e HCO3=28,7). Devido a essa piora, solicitou-se pesquisa de BAAR, curva térmica de 4 em 4 horas e tomografia computadorizada sem contraste. Além disso, acrescentaram Vancomicina 1g EV de 12 em 12 horas à antibioticoterapia e iniciaram suporte ventilatório através de $\mathrm{O}_{2}$ por cateter nasal.

Houve boa resposta terapêutica, resultando em uma evolução de melhora do quadro respiratório, sem distúrbios hemodinâmicos e com remissão das lesões cutâneas. No décimo sexto dia ao receber alta, foi referenciado ao Centro de Especialidades Médicas de Aracaju (Cemar) para realizar acompanhamento 
com um médico infectologista, dando continuidade ao tratamento com COXCIP, Bactrim, Azitromicina e antirretrovirais.

A Leishmaniose cutânea disseminada (LCD) é uma forma extremamente rara de apresentação da infecção por leishmânia, tendo um fenótipo bastante semelhante entre pacientes imunocompetentes e pacientes com coinfecção HIV-Leishmânia. Geralmente, nos pacientes coinfectados, a contagem CD4 é muito baixa (inferior a 200 céls $/ \mathrm{mm}^{3}$ ) e o teste sorológico negativo, sendo a principal diferença em relação aos pacientes sem imunossupressão. No paciente do relato, apesar do padrão esperado de reatividade negativa e bicitopenia relacionado à infecção, não havia linfopenia a nível esperado para infecções oportunistas com o nível de gravidade da LCD, com resultados entre 439 e 564 células durante o seu período de internamento.

\section{CONCLUSÕES}

Supõe-se que o desvio da resposta celular tipo Th1 para a humoral tipo Th2 no portador de HIV seja favorável à disseminação de organismos intracelulares como a leishmania. Entretanto, esse comportamento clínico-imunológico da coinfecção é pouco descrito na literatura. Ainda assim, J.B.A. apresentou excelente resposta terapêutica ao uso de Anfotericina Lipossomal. O relato desse caso alerta para o espectro clínico da coinfecção e para uma opção de tratamento viável, sobretudo em Sergipe, cuja expansão epidemiológica das doenças é evidente.

\section{REFERÊNCIAS}

ALVAR, J.. The relationship between leishmaniasis and AIDS: the second 10 years. Clinical microbiology reviews, v.21, n.2, p.334-359, 2008.

BASANO, S. A.; CAMARGO, L. M. A.. Leishmaniose tegumentar americana: histórico, epidemiologia e perspectivas de controle. Revista Brasileira de Epidemiologia, v.7, p.328-337, 2004.

BRASIL. Ministério da Saúde. Manual de vigilância da leishmaniose tegumentar americana. Brasília: Ministério da Saúde, 2007.

KUMARI, A.. Diffuse cutaneous leishmaniasis in an immunocompromised patient resembling histoid Hansen's disease. Indian Dermatology Online Journal, v.9, n.6, p.452, 2018.

LIMA, E. B.. Tratamento da leishmaniose tegumentar americana. Anais Brasileiros de Dermatologia, v.82, n.2, p.111-124, 2007.
BRASIL. Ministério da Saúde. Guia de vigilância epidemiológica, 2009.

TANGIE, L. N.. Cutaneous leishmaniasis in a severely immunocompromised HIV patient in Kumbo, Northwest region of Cameroon: case report. BMC research notes, v.10, n.1, p.1-4, 2017

\section{TA, F.. Doenças infecciosas com manifestações dermatológicas. Rio de Janeiro: Medsi, 1994.}

GRIENSVEN, J. V.. Leishmaniasis in immunosuppressed individuals. Clinical Microbiology and Infection, v.20, n.4, p.286-299, 2014.

ZIJLSTRA, E. E.. PKDL and other dermal lesions in HIV coinfected patients with Leishmaniasis: review of clinical presentation in relation to immune responses. PLoS Negl Trop Dis, v.20, n.8, 2014. DOI: http://doi.org/10.1371/journal.pntd.0003258

A CBPC - Companhia Brasileira de Produção Científica (CNPJ: 11.221.422/0001-03) detém os direitos materiais desta publicação. Os direitos referem-se à publicação do trabalho em qualquer parte do mundo, incluindo os direitos às renovações, expansões e disseminações da contribuição, bem como outros direitos subsidiários. Todos os trabalhos publicados eletronicamente poderão posteriormente ser publicados em coletâneas impressas sob coordenação da Sustenere Publishing, da Companhia Brasileira de Produção Científica e seus parceiros autorizados. Os (as) autores (as) preservam os direitos autorais, mas não têm permissão para a publicação da contribuição em outro meio, impresso ou digital, em português ou em tradução. 